\title{
Drilling mud with addition of new hydration inhibitor for clay rocks
}

\author{
Stawomir Wysocki ${ }^{1}$, Magdalena Gaczo1 ${ }^{1,{ }^{*}}$ and Marta Wysocka $^{1}$ \\ ${ }^{1}$ AGH-University of Science and Technology Krakow, Faculty of Drilling, Oil and Gas, Al. Mickiewicza 30. 30-059 Kraków
}

\begin{abstract}
While drilling through clay rocks using water-based mud, number of challenges need to be faced in view of hydration and swelling of this type of rock. Those phenomena consist in the fact, that clay mineral grows in volume due to water contact. In order to limit hydration phenomenon, for clay rocks drilling are used drilling muds with addition of chemical agents called hydration inhibitors. The article describes studies, which resulted in development of new formula of drilling mud with addition of a new short-chained amino polymer developed in Drilling, Oil and Gas Faculty AGH-UST Krakow. For the developed mud, tests of technological parameters were conducted according to API RP 13B-1 as well as specialist examinations: linear swelling of Miocene shale and clay rock disintegration. Studies also consists of syntheses of polyampholyte and short-chained cationic polymer. Based on performed studies, it was found that studied mud is characterized by good and easy to regulate technological parameters as well as effective inhibition of hydration, swelling and disintegration of clay rocks.
\end{abstract}

\section{Introduction}

While drilling through clay rocks, numerous issues can be encountered due to structure and features of this type of rock. Clay rocks usually exhibit platelet structure. During drilling of abovementioned rocks using waterbased mud, water originated from the mud infiltrates into interlayer spaces causing swelling of the rock.

Clay rock hydration phenomenon occurs in two phases (Fig. 1). Initial phase - surface hydration - lasts for 1 to $24 \mathrm{~h}$ and embraces 3-5 first layers of clay platelets. In this phase, infiltration of the water into clay rock and its swelling can be observed. Consequently, the rock expands upon a borehole what can lead to borehole wall diameter decrease, circulation losses and stuck of a pipe [1]. Second phase - osmotic hydration - consists in infiltration of the water into deeper layers of the rock via osmosis phenomenon. Further swelling of the rock can cause its caving. For this reason, several problems arise, ex. tight borehole and stuck collars, poor borehole cleaning, poor logging and cementing and difficulties in returning drilling assembly to the bottom [1].

In order to minimize issues related to hydration and swelling phenomena, special agents are used in the muds for clay rock drilling. Relatively best effects are obtained with oil-based muds (OBM), however its application can be limited due to environmental considerations and high costs. Hence, nowadays, studies on development of new and enhancement of existing water-based mud are conducted. For drilling through clay rock, muds with application of hydration inhibitors are used. Early formulas of abovementioned mud applied ionic inhibitors: potassium and calcium ions. Next, muds with dual inhibition system were in common use: polymericpotassium, glycolic-potassium etc. Currently, for clay rock drilling muds with triple inhibition system are used, commonly glycol-potassium-polymeric. Polymeric inhibitor in such system is a partially hydrolyzed polyacrylamide (PHPA). PHPA polymer is relatively effective hydration inhibitor, however it is not perfect solution and often its presence in the mud can generate problems. Due to carboxyl groups, PHPA is not resistant to mono- and multivalent contamination, this may cause its salting out. Because PHPA in low concentrations acts as an effective flocculant, local lowering of its concentration can in turn lead to flocculation of the mud in the borehole what is in turn a dangerous phenomenon. High molecular masses of PHPA causes that it can cause clogging of the porous spaces. This and application of polyglycols (which fall out of the mud at raised temperature) causes that abovementioned mud cannot be used for drill-in operations. Due to this, it is beneficial to replace PHPA in drilling mud formula with other polymeric inhibitor. Studies has led to development of new kind of water-based mud known as a HPWBM (High Performance Water-based Muds). Those muds contain in its formula, amine agents, among others: tetra alkyl ammonium salts, polyamine acids, polyhydroxylated alkyl ammonium salts, hexamethylenediamine, polyetherdiamines, lipophilic amines [2] as well as cationic polymers [3]. Carried out studies [4] showed that adsorption of quaternary polyamines on bentonite molecules is four times higher than polyacrylamide [5].

\footnotetext{
* Corresponding author: mgaczol@agh.edu.pl
} 


\section{A. Nonhydrationed molecules of clay}

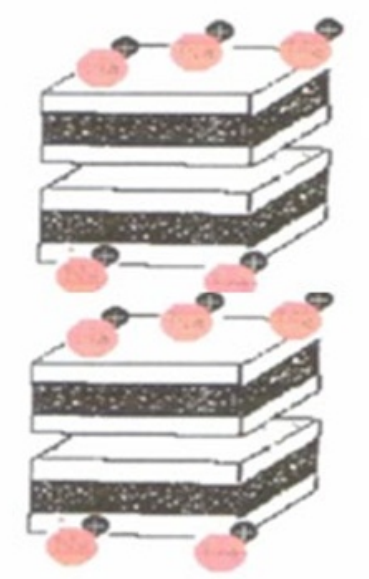

Sodium cations

Water molecules

\section{B. Surface hydration}

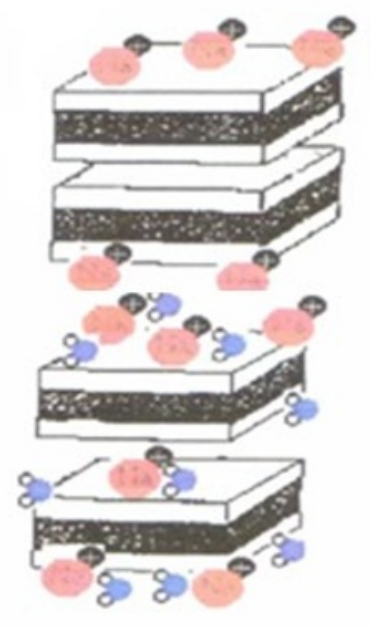

C. Osmotic hydration

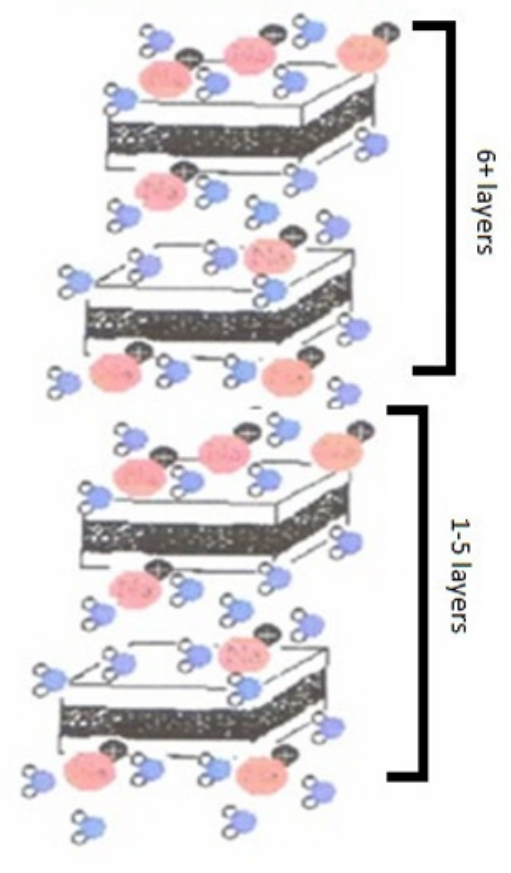

Fig. 1. Shale hydration process.

Numerous studies carried out worldwide $[5,6]$ as well as authors own studies confirmed effectiveness of ammonium chloride as ionic inhibitor of clay rock hydration. However, application of ammonium chloride in the mud with high $\mathrm{pH}$ value is very limited due to possibility of ammonia release. Additionally, ammonium chloride is highly corrosive agent what influences negatively condition of the tubulars and can lead to its damage. In order to exploit advantages and avoid disadvantages of $\mathrm{NH}_{4} \mathrm{Cl}$, at the Drilling, Oil and Gas Faculty AGH-UST in Krakow are conducted syntheses of low-molecular cationic polymers with primary amino groups and low steric hindrance as well as tests of its application in the muds intended for clay rocks drilling.

The article describes findings of the research on development of new drilling mud with application of high-molecular ampholytic polymer and low-molecular cationic polymer with primary amino groups for clay rocks drilling. Syntheses of both polymers were undertaken at Drilling, Oil and Gas Faculty AGH-UST in Krakow.

\section{Methodology of the research}

\subsection{Test of technological parameters}

Tests of technological parameters (apparent viscosity, plastic viscosity, yield point, geles and filtration) of drilling muds were undertaken according to API standards [7]. Additionally, tests of thermal resistance were performed with the thermo cup designed for rotational viscometer.

\subsection{Linear swell test}

Linear swell tests have been achieved with GRACE Instrument M4600 HPHT Linear Swell Meter. Samples of powdered rock (Miocene shale) with weight of about 11 grams were placed in M4600 Dual Core/Wafer Compactor cells and have been pressurized at $2500 \mathrm{psi}$ for 60 minutes. Pellets obtained that way were placed in GRACE Instrument M4600 HPHT Linear Swell Meter measuring cells which were subsequently immersed in studied fluid. Test of swelling was conducted for $6 \mathrm{~h}$ under $20^{\circ} \mathrm{C}$ temperature and atmospheric pressure.

\subsection{Test of clay rock disintegration}

$350 \mathrm{ml}$ of studied drilling mud and 50 grams $(\mathrm{m})$ of prepared clay rock sample with granulation of $1.5-5$ $\mathrm{mm}$ were immersed in the autoclave of $500 \mathrm{ml}$ volume. Autoclave was conditioned in Rolen-Oven for $16 \mathrm{~h}$ at temperature of $20^{\circ} \mathrm{C}$. After that period of time, autoclave content was sieved through a sieve with $0.5 \mathrm{~mm}$ mesh. Residues remained on the sieve were washed with water in order to remove leftovers of the mud or polymer solution, next it was dried (to constant mass) and weighted with accuracy of 0.01 gram $\left(m_{p}\right)$. Dried and weighted sample was again putted into autoclave and poured with $350 \mathrm{ml}$ of tap water. Autoclave was conditioned in the rotary oven for 2 hours at temperature of $20^{\circ} \mathrm{C}$, subsequently its content was separated also through sieve with $0.5 \mathrm{~mm}$ mesh. Residues left on the sieve were dried to constant mass and weighted with accuracy of 0.01 gram $\left(m_{w}\right)$.

The result of the dispersion test is percentage ratio of weight of the sample remained on sieve after $16 \mathrm{~h}$ of 
dispersion in the drilling mud to the total weight of sample used for test, marked as $P_{l}$ and also a ratio of weight of the sample remained on sieve after $16 \mathrm{~h}$ of dispersion in the water to the total weight of sample used for test, marked as $P_{2} . P_{1}$ and $P_{2}$ values are calculated with equations:

$$
\begin{aligned}
& P_{1}=\left(m_{p} \cdot 100\right) / m, \% \\
& P_{2}=\left(m_{w} \cdot 100\right) / m, \%
\end{aligned}
$$

\section{Materials used in the research}

Chemical agents used for the studies: PAmf-07 - highmolecular polyampholyte synthesized at Drilling, Oil and Gas Faculty; EmP-01 - blend of cross-linked starch and polyampholyte, formula prepared at Drilling, Oil and Gas Faculty; GER-012 - low-molecular cationic polymer synthesized at Drilling, Oil and Gas Faculty; $\mathrm{KHCO}_{3}$ - potassium hydrogen carbonate, carbonate bridging agent $\phi=25 \mu \mathrm{m}, \mathrm{KCl}$ - potassium chloride, ammonium persulfate, $\mathrm{HCl}$ - hydrochloric acid, $\mathrm{KOH}-$ potassium hydroxide, $\mathrm{NaCl}$ - sodium chloride (supplier: PSPW Krosno); $\mathrm{MgCl}_{2} \bullet 6 \mathrm{H}_{2} \mathrm{O}$ - magnesium chloride (supplier: Avantor Performance Materials Poland S.A.); $\mathrm{CaCl}_{2}$ - calcium chloride (supplier: Avantor Performance Materials Poland S.A.); AIBN - azobisisobutyronitrile (supplier: Sigma-Aldrich).

\section{Synthesis of the polymers}

\subsection{Synthesis of PAmf-07}

Synthesis of PAmf-07 polyampholyte was carried out by a radical polymerization with application of AIBN (azobisisobutyronitrile) as an initiator. Monomers solution was placed in reaction round-bottomed flask and heated up to $70^{\circ} \mathrm{C}$. Reaction was carried out for $7 \mathrm{~h}$, then obtained polymer solution was left for 24 hours. After this period of time, polymer was hydrolyzed with hydrochloric acid. Polymer solution was neutralized by addition of potassium hydroxide and used as obtained.

\subsection{Synthesis of GER-012}

Synthesis of GER-012 cationic polymer was carried out by a radical polymerization with application of ammonium persulfate as an initiator. Monomers solution was placed in reaction round-bottomed flask and heated up to $50^{\circ} \mathrm{C}$. Reaction was carried out for $7 \mathrm{~h}$, then obtained polymer solution was left for $24 \mathrm{~h}$. After this period of time, polymer was hydrolyzed with potassium hydroxide. Polymer solution was neutralized by addition of hydrochloric acid and used as obtained.

\section{Development of the drilling mud}

\subsection{Selection of EmP-01 structure-forming agent concentration}

In the framework of base mud development, blend of two polymers (EmP-01) was prepared. The blend is a combination of cross-linked starch and anionic-cationic polymer synthesized at Drilling, Oil and Gas Faculty AGH-UST. Technological parameters of the mud were examined in order to verify its validity. Results of the chosen mud are presented in Fig. 2. The mud was studied in blend range of concentrations of $2.0-3.5 \%$ w/w. Technological parameters of mud chosen for further studies are summarized in Tab. 1.
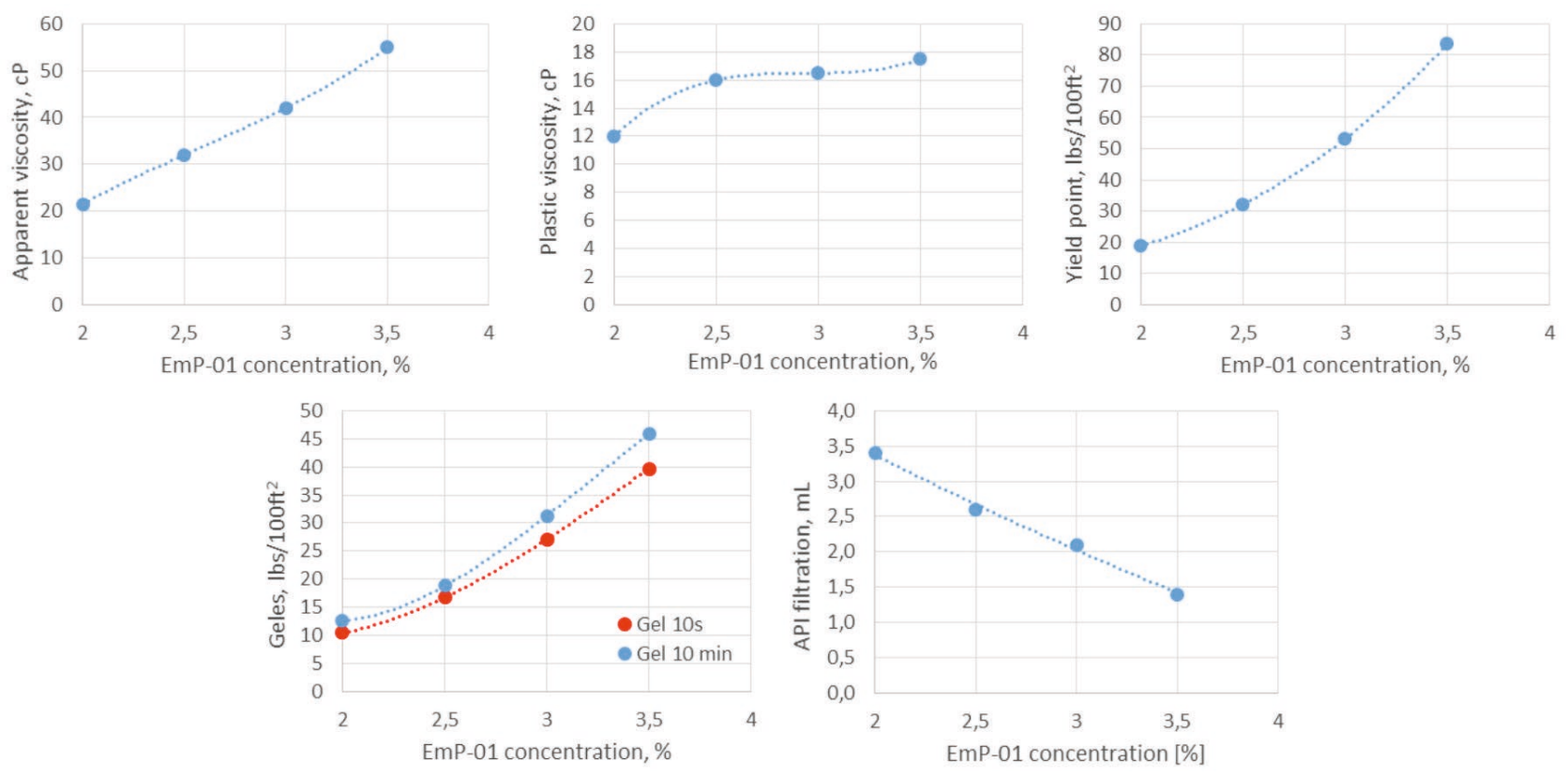

Fig. 2. Influence of EmP-01 concentration on technological properties of base mud. 
Table 1. Formula and technological parameters of base mud.

\begin{tabular}{|l|l|}
\hline \multicolumn{2}{|l|}{ Drilling mud formula } \\
\hline EmP-01 & $2.5 \%$ \\
\hline KHCO3 & $\mathrm{pH} \sim 10$ \\
\hline Bridging agent & $10.0 \%$ \\
\hline KCI & $3.0 \%$ \\
\hline Technological parameters \\
\hline Plastic viscosity & $16 \mathrm{cP}$ \\
\hline Aparent viscosity & $32 \mathrm{cP}$ \\
\hline Yield point & $32.2 \mathrm{lb} / 100 \mathrm{ft}^{2}$ \\
\hline Geles & $18.8 / 16.7 \mathrm{lb} / 100 \mathrm{ft}^{2}$ \\
\hline API Filtration & $2.6 \mathrm{~mL}$ \\
\hline
\end{tabular}

\subsection{Influence of GER-012 concentration on technological properties of base mud}

Next, influence of GER-012 polymer on mud technological parameters was tested. Studied polymer was added to the mud in concentrations of $0-0.75 \%$ w/w. Results are presented in Fig. 3. Technological parameters of mud chosen for further studies are summarized in Tab. 2.
Table 2. Formula and technological parameters of developed mud.

\begin{tabular}{|l|l|}
\hline \multicolumn{2}{|l|}{ Drilling mud formula } \\
\hline EmP-01 & $2.5 \%$ \\
\hline GER-012 & $0.25 \%$ \\
\hline KHCO $_{3}$ & $\mathrm{pH} \sim 10$ \\
\hline Bridging agent & $10.0 \%$ \\
\hline KCI & $3.0 \%$ \\
\hline Technological parameters \\
\hline Plastic viscosity & $18 \mathrm{cP}$ \\
\hline Aparent viscosity & $38 \mathrm{cP}$ \\
\hline Yield point & $40.1 \mathrm{lb} / 100 \mathrm{ft}^{2}$ \\
\hline Geles & $17.8 / 20.9 \mathrm{lb} / 100 \mathrm{ft}^{2}$ \\
\hline API Filtration & $2.4 \mathrm{~mL}$ \\
\hline
\end{tabular}

\subsection{Influence of GER-012 concentration on technological properties of base mud}

For assessment of developed mud resistance to monoand divalent contamination, two tests were performed. Each consists of technological parameters examinations of muds with addition of three different salts $(\mathrm{NaCl}$, $\left.\mathrm{CaCl}_{2}, \mathrm{MgCl}_{2} \bullet 6 \mathrm{H}_{2} \mathrm{O}\right)$.

\subsubsection{Monovalent ions contamination}

Firstly, muds with addition of sodium chloride in concentrations of $5-30 \% \mathrm{w} / \mathrm{w}$ were prepared and its technological parameters were measured. Results are presented in Fig. 4.
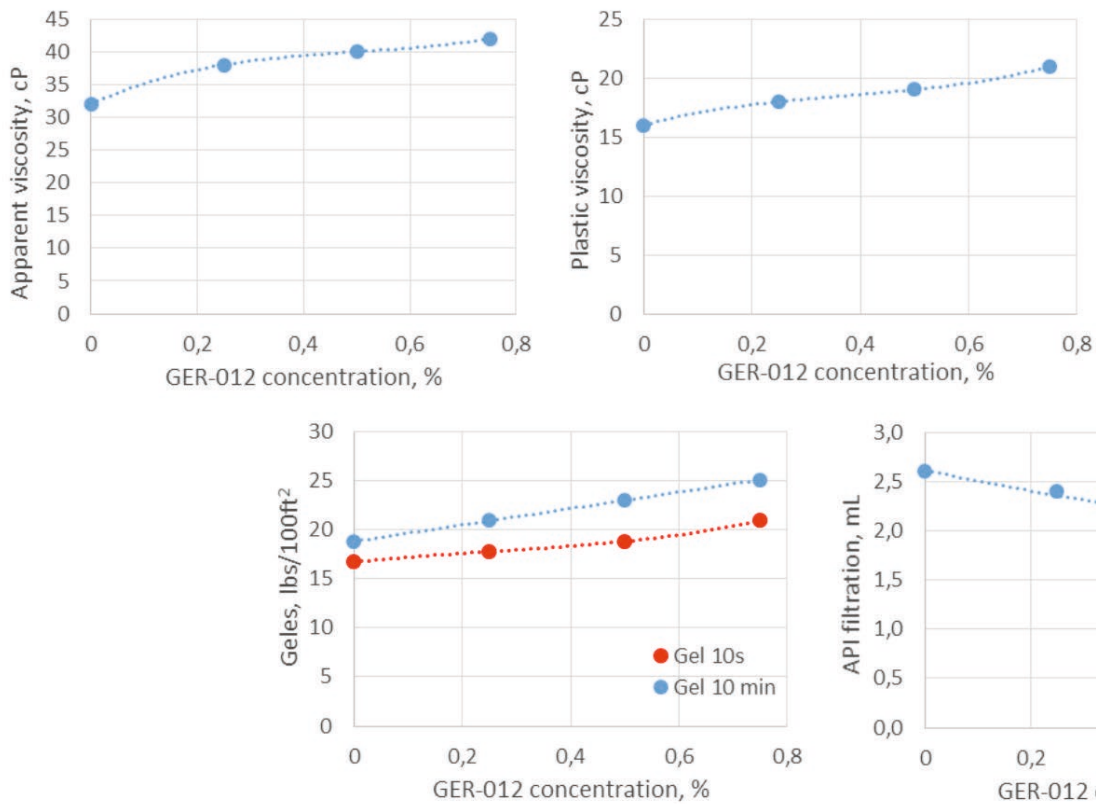
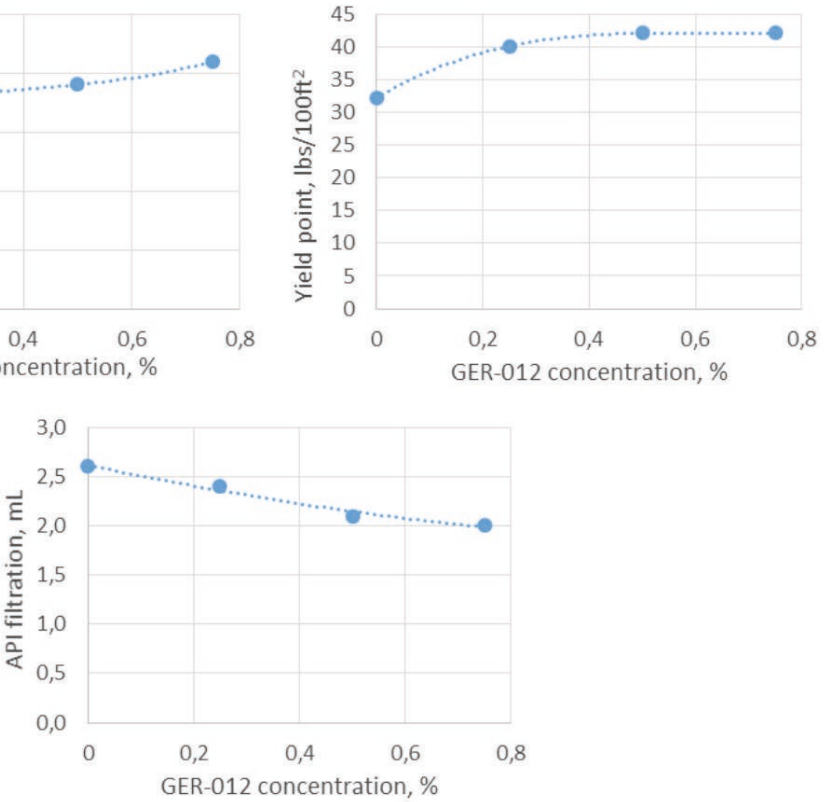

Fig. 3. Influence of GER-012 concentration on technological properties of base mud. 

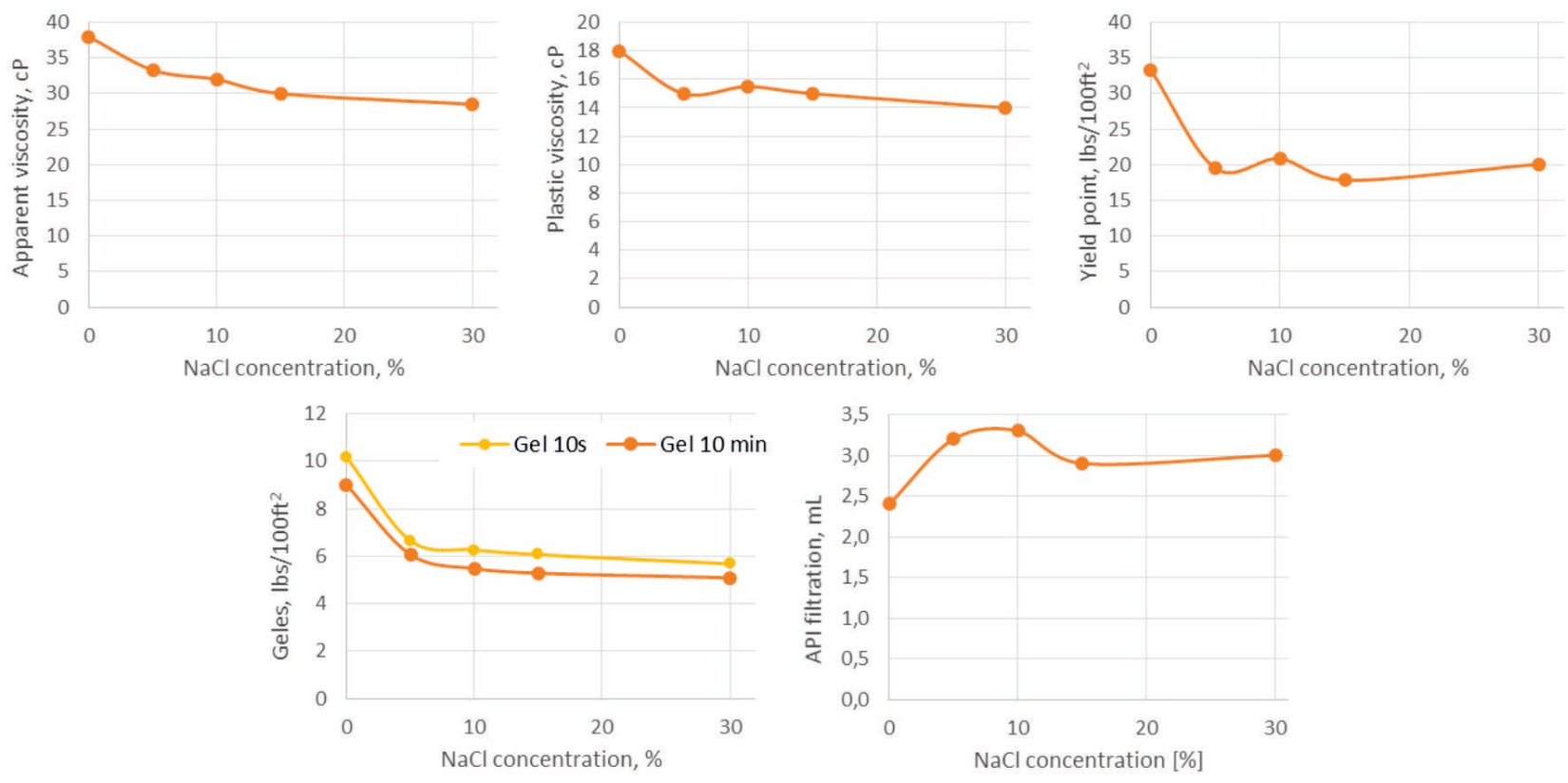

Fig. 4. Resistance of developed mud to monovalent ions.
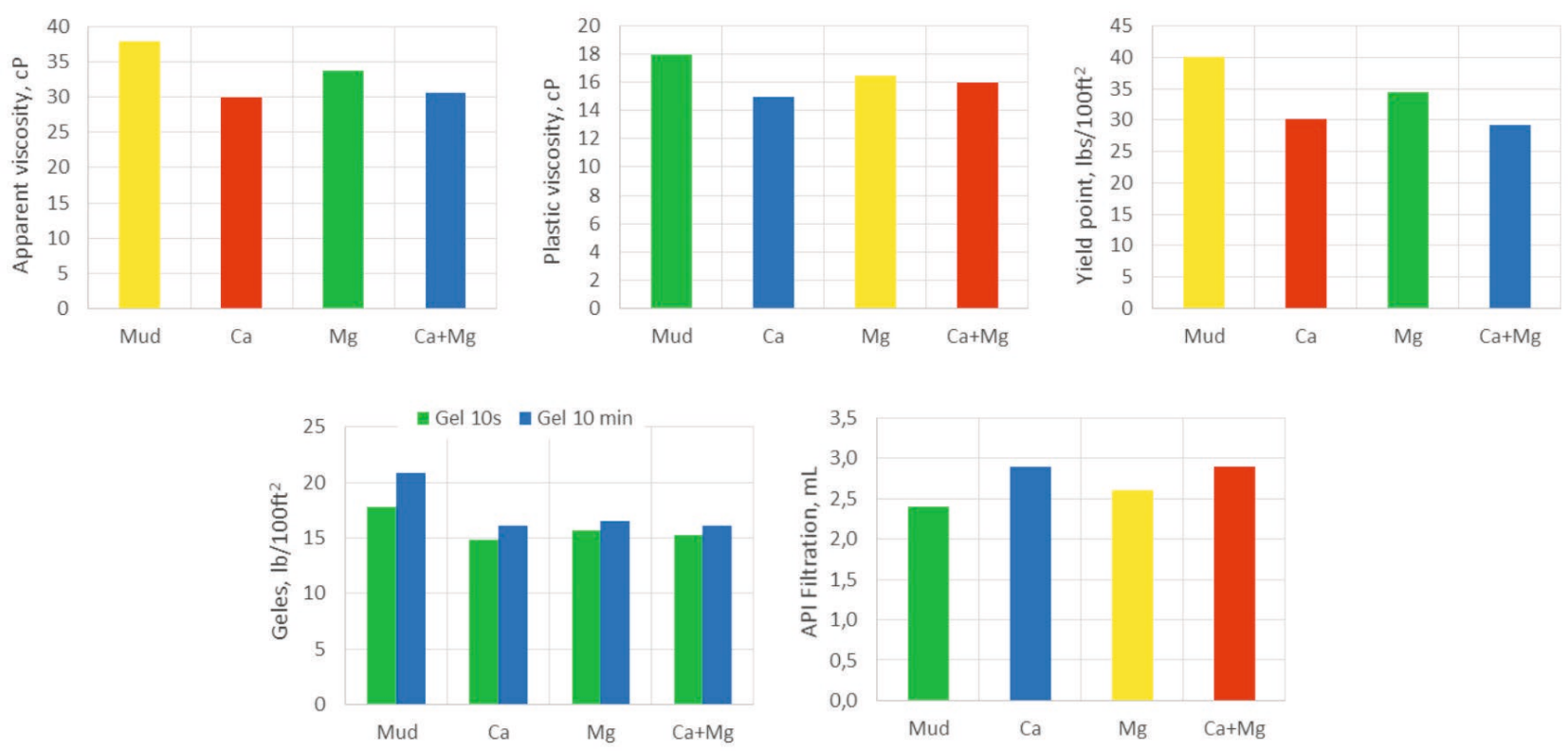

Fig. 5. Resistance of developed mud to divalent ions.

\subsubsection{Divalent ions contamination}

Next, influence of divalent ions on developed mud was tested. Four muds were studied: developed mud and muds with addition of $0.5 \% \mathrm{CaCl}_{2}, 0.5 \% \mathrm{MgCl}_{2} \cdot 6 \mathrm{H}_{2} \mathrm{O}$ and its combination). Then its technological parameters were examined. Results are presented in Fig. 5.

\subsection{Thermal resistance of the developed mud}

In order to examine thermal resistance of developed mud, its rheological properties were tested in temperature range of $20-90^{\circ} \mathrm{C}$. Results are presented in Fig. 6.

\subsection{Inhibitive properties of studied mud}

Further stage of the studies includes examinations of inhibitive properties of studied mud. Three different tests were carried out for base mud with addition of synthesized GER-012 polymer.

\subsubsection{LST}

In order to validate inhibitive properties of developed mud, test of Miocene shale linear swelling under influence of the mud was undertaken. Results are presented in Fig. 7. 

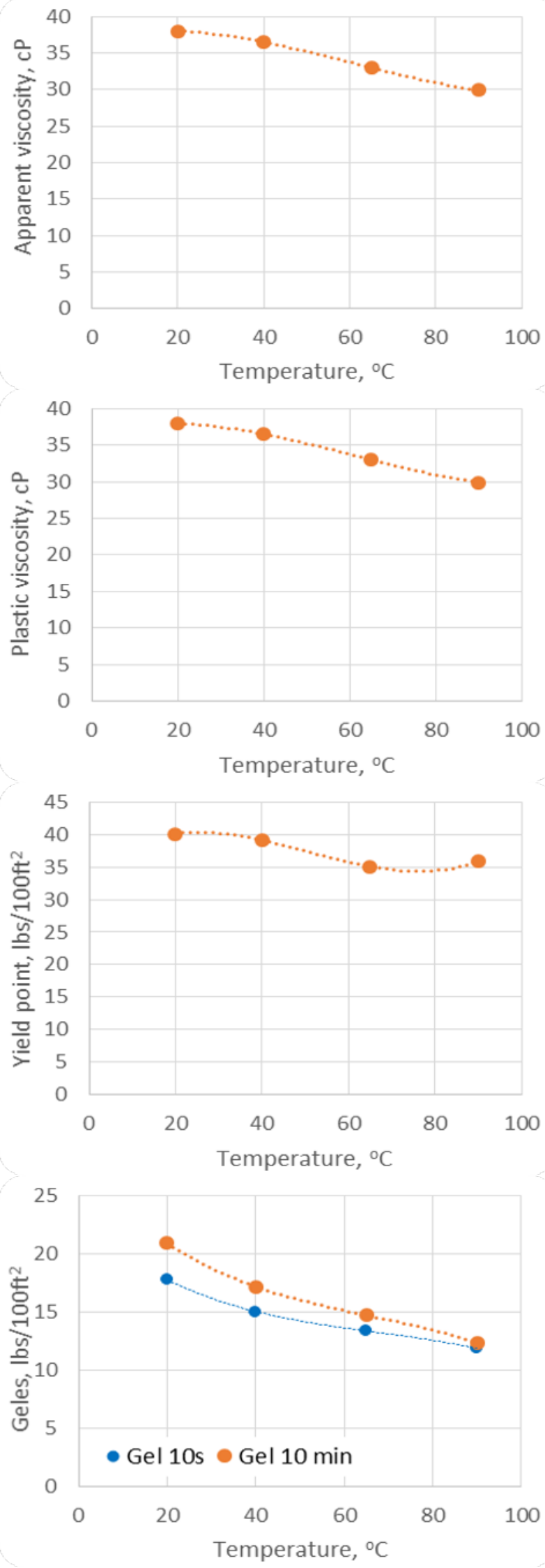

Fig. 6. Resistance of developed mud to temperature.

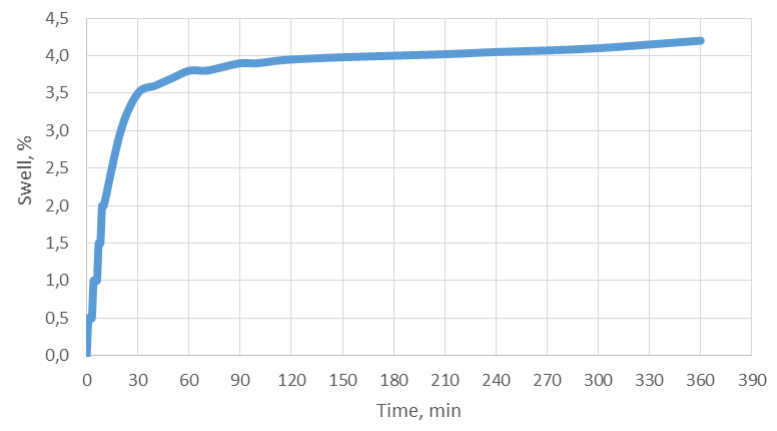

Fig. 7. Linear swelling of developed mud.

\subsubsection{Disintegration of clay rock sample influenced by studied mud}

Tests of Miocene shale disintegration under influence of developed mud have been carried out. Test results are presented in Fig. 8.

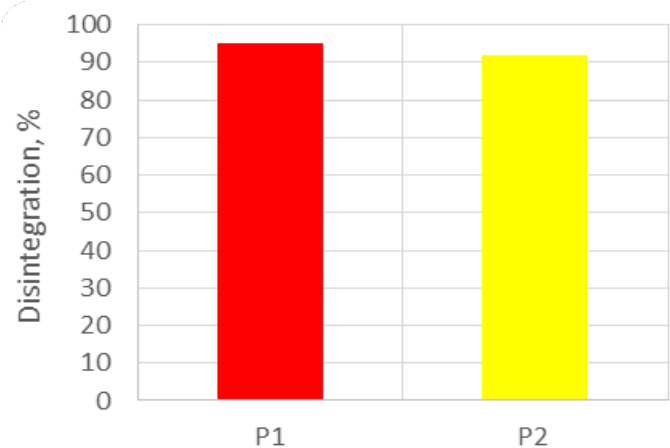

Fig. 8. Disintegration of Miocene shale sample influenced by studied mud.

\section{Discussion of the research results}

In first stage of the project, synthesis of two polymers were performed: PAmf-07 polyampholyte and GER-012 polycationite. Formula of polymeric agent was based on PAmf-07 polyamphotyle and cross-linked starch, its role is providing structure and good rheological properties of the drilling mud. Undertaken studies showed that developed agent (EmP-01) enables to prepare a mud possessing satisfying rheological properties which can be regulated by changing the EmP-01 agent concentration. Mud with concentration of $2.5 \% \mathrm{w} / \mathrm{w}$ was selected for further studies. Next, influence of GER-012 polycationite concentration on rheological properties of the mud was examined. Based on the test results, it can be concluded that increase of applied polymer concentration insignificantly changes parameters of the mud. For further studies, mud with addition of $0.25 \%$ concentration $\mathrm{w} / \mathrm{w}$ of the GER-012 polymer was selected. Studies allowed development of the mud formula (Tab. 2) which was used for further tests.

Subsequent stages of the project consist in tests of developed mud resistance to mono- and divalent ions contamination as well as temperature and effectiveness of clay rock hydration inhibition. 
Performed tests showed that developed mud is relatively resistant to monovalent ions contamination. It can be observed insignificant changes of viscosity parameters and slightly higher changes of strength parameters, however all of them remain at sufficient level. Good resistance of the mud to monovalent contamination is confirmed by very low increase of filtration value. Carried out tests showed also considerably high resistance of developed mud to divalent contamination. Addition of calcium and magnesium ions to the mud results in slight change of its rheological properties and filtration.

Moreover, resistance of developed mud to raised temperature was studied. Undertaken studies showed that developed mud is resistant to high temperatures. Its rheological properties are decreasing due to temperature elevation, however do not change significantly.

Last stage of the project was an examination of clay rock hydration inhibition by developed mud. Performed tests of Miocene shale linear swelling confirmed effective inhibitive properties of mud with GER-012 polymer addition. First period of test (about $30 \mathrm{~min}$ ) showed rapid increase of Miocene shale swelling, however final result after $360 \mathrm{~min}$ maintain at low level of $4.2 \%$. Satisfactory results achieved for LST were then confirmed by outcome of Miocene shale disintegration test. $95 \%$ recovery of the shale after influence of mud and $92 \%$ after washing with water shows that performance of applied polymers is highly effective.

\section{Summary}

PAmf-07 is a high-molecular poliampholyte containing in its chain mers with anionic sulpho groups and cationic mers with primary amino groups. Therefore, the structure assures resistance to mono- and multivalent ions. Due to high molecular masses, PAmf-07 effectively increases rheological properties (plastic and apparent viscosity) of drilling mud. Moreover, by reason of cationic groups, occurring in the molecule, PAmf-07 can effectively absorb at borehole wall and cuttings (which are negatively charged), what impedes water penetration from drilling mud to rock/filtrate. In this case, polyampholyte acts as an encapsulating polymer.

Combination of PAmf-07 polymapholyte and crosslinked starch with increased resistance to temperature, has led to development of formula of agent enabling preparation of a mud with good and easy to regulate rheological properties, resistant to mono- and divalent contamination and temperature up to $150^{\circ} \mathrm{C}$.

GER-012 is a cationic polymer, which contains in its chain mers with primary amino groups. It is a polymer with low molecular mass of about $50,000 \mu$. Therefore, the structure provides effective inhibition of clay rock hydration. Amino groups occurring at chain ends, due to low steric hindrance, can penetrate into interlayer spaces of clay rock. Thus, they act as an ionic inhibitor. Additional, chains of the polymer, adsorbed at different layers of the clay mineral, guarantee mechanical stabilization. Schematic behaviour of the GER- 012 polymer is presented in Fig. 9.

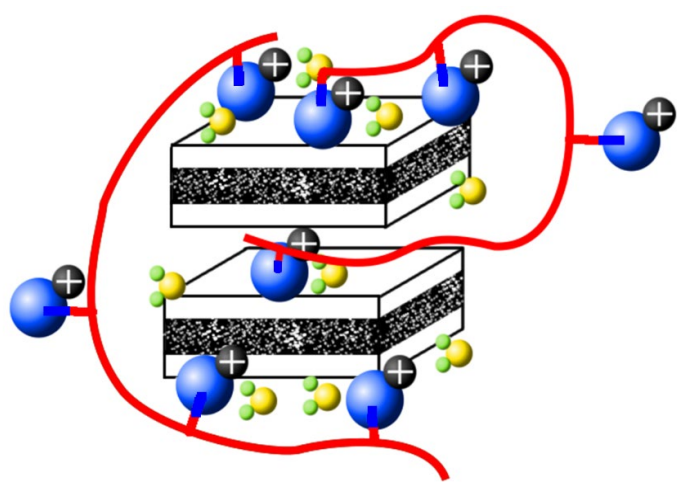

Fig. 9. Shale rock stabilization using polycationite.

Low molecular mass of GER-012 polymer causes that increase of its concentration in the mud does not influence significantly rheological properties of the mud. Due to this, in case of such need, inhibiting properties of the mud can be raised by increasing GER-012 polymer concentration, without concerns about rheology changes.

In the framework of the project, formula of mud intended for clay rock drilling was developed. Structure and rheology of developed mud are based on EmP-01 agent which was applied in $2.5 \%$ concentration w/w. In order to protect clay rocks against hydration, GER-012 polymer and ionic inhibitor $(\mathrm{KCl})$ were used. Value of mud $\mathrm{pH}$ was increased to $\mathrm{pH} \sim 10$ with potassium hydrogen carbonate. Furthermore, carbonate bridging agent was added to mud formula. This composition of the mud allows obtaining a good rheological properties. Developed mud is characterized by satisfying resistance to mono- and divalent salts contamination as well as to raised temperature and effective clay rock hydration inhibition. Elimination of PHPA polymer from the mud formula and application of carbonate bridging agent enables application of developed mud not only for clay rock drilling, but also for drill-in operations (drill-in fluid).

Paper prepared within the statutory research program of the Faculty of Drilling, Oil and Gas, AGH University of Science and Technology No. 11.11.190.555.

\section{References}

1. M. E. Chenevert, S. O. Osisanya, SPE Drilling Engineering, (September 1989)

2. A. Patel, S. Young, J. Friedheim, SPE 106476 (2007)

3. S. Carminati, L. Del Gaudio, G. Del Piero, M. Brignoli, SPE 65001 (2001)

4. R.H. Retz, J. Friedheim, L. J. Lee, O. O. Welch, SPE 23064 (1991)

5. T. AlMubarak, O. AlDajani, M. AlMubarak, IPTC18394-MS (2015)

6. I. A. El-Monier, H. A. Nasr-El-Din, R. L. Rosen, T. L. Harper, SPE 136061 (2013)

7. API RP 13B-1, 3rd Edition (December 2003) 